\title{
Segmental Overgrowth Syndrome Due to an Activating PIK3CA Mutation Identified in Affected Muscle Tissue by Exome Sequencing
}

\author{
Maria Rasmussen, ${ }^{1 *}$ Lone Sunde, ${ }^{1}$ Karen Petra Weigert, ${ }^{2}$ Pauline Wilhemina Bogaard, ${ }^{3}$ \\ and Dorte L. Lildballe ${ }^{1}$ \\ ${ }^{1}$ Department of Clinical Genetics, Aarhus University Hospital, Skejby, Aarhus, Denmark \\ ${ }^{2}$ Department of Orthopedic Surgery, Aalborg University Hospital, Aalborg, Denmark \\ ${ }^{3}$ Department of Pathology, Aalborg University Hospital, Aalborg, Denmark
}

Manuscript Received: 10 November 2013; Manuscript Accepted: 5 January 2014

Mosaic PIK3CA-mutations have been described in an increasing number of overgrowth syndromes. We describe a patient with a previously unreported segmental overgrowth syndrome with the mutation, PIKCA3 c.3140A $>$ G (p.His1047Arg) in affected tissue diagnosed by exome sequencing. This PIK3CA-associated segmental overgrowth syndrome overlaps with CLOVES syndrome and fibroadipose hyperplasia but is distinct from each of these entities. () 2014 Wiley Periodicals, Inc.

Key words: CLOVES; PIK3CA; overgrowth; fibroadipose hyperplasia

\section{INTRODUCTION}

Non-cancerous somatic mosaicism for activating mutation in the PIK3CA gene was first reported in CLOVES syndrome. CLOVES syndrome was initially described by Sapp et al. [2007] who named it congenital lipomatous overgrowth, vascular malformations, and epidermal nevi syndrome (CLOVE syndrome). Later, Alomari [2009] argued for the addition of an S-an acronym for Skeletal and Spinal anomalies. Most recently, CLOVES syndrome has been categorized as a PIK3CA-associated segmental overgrowth, which also includes megalencephaly/hemimegalencephaly capillary malformation syndrome and fibroadipose hyperplasia [Mirzaa et al., 2013]. Fibroadipose hyperplasia was described by Lindhurst et al. [2012] as congenital, progressive segmental overgrowth of fibrous and adipose tissue and bone. Here, we present a patient with segmental symmetric overgrowth of the hands, arms, shoulders, and neck, and a lipomatous mass on the upper back, shoulder and neck, completely sparing the head, lower body, and legs. The involved tissues primarily include lipomatous and muscular tissue.

\section{CLINICAL REPORT}

A 20-year-old Caucasian woman was referred to the department of clinical genetics with an unknown segmental overgrowth syndrome. She was born at 39 weeks gestation by cesarean due to prolonged labor. The mother did not experience any illness during
How to Cite this Article:

Rasmussen M, Sunde L, Weigert KP, Bogaard PW, Lildballe DL. 2014. Segmental overgrowth syndrome due to an activating PIK3CA mutation identified in affected muscle tissue by exome sequencing. Am J Med Genet Part A 164A:1318-1321.

pregnancy, nor did she take any medication and she suffered of no drug or alcohol abuse. The family history was unremarkable. The patient's birth weight was 3,160 g ( 25th centile) and the length was $50 \mathrm{~cm}$ ( $\sim 50$ th centile). At birth, she presented with enlarged arms and broad palms as well as a mass on her upper back. Ultrasound examination of the mass in the neonatal period identified it as a lipomatous mass. The mass dramatically increased in size during the neonatal period and the patient developed neck webbing. Otherwise, the neonatal period was uneventful.

The patient was considered to have Proteus syndrome from the age of 15 months. When the patient was 10 years old, the diagnosis was changed to "an unknown segmental overgrowth syndrome."

Throughout childhood, the patient experienced fast wound healing and increased strengths in her arms and neck compared to children of similar age. The patient had progressive contractures of the palms and fingers compromising the grip of the hands and the ability to actively straighten out the hands and fingers. Furthermore, the index finger on the right hand overlapped the middle finger when flexed in the metacarpophalageal joint. Orthopedic

Conflict of interest: none.

*Correspondence to:

Maria Rasmussen, Department of Clinical Genetics, Aarhus University Hospital, Skejby, Brendstrupgaardsvej 21C, 8200 Aarhus, Denmark.

E-mail: marirasm@rm.dk

Article first published online in Wiley Online Library

(wileyonlinelibrary.com): 24 March 2014

DOI 10.1002/ajmg.a.36454 
examination suggested that the dysfunction was due to missing transverse metacarpal ligaments.

The patient was an active sport enthusiast, but small traumas seemed to cause excessively long periods of swellings in the traumatized areas, and on some occasions the expansion of the muscles persisted. Likewise, surgical procedures of the hands have been followed by persistent muscular enlargement.

At the ages of 11 months, 15 months, 5 years, and 15 years the patient underwent liposuction of the lipomatous mass. Every procedure was followed by regrowth and even expansion of the mass. At the last procedure the surgeon was unable to remove much of the mass since the lipomatous tissue had infiltrated the muscles. Most recently, the patient was evaluated for further debulking surgery.

Magnetic resonance images (MRIs) when the patient was 21 years old demonstrated cervical scoliosis and the large lipomatous mass at the upper thoracic region infiltrating the back, shoulder, and cervical muscles. The cervical muscles were undergrown and displaced laterally from the lipomatous tissue, while the muscles of the shoulders were enlarged. Further, the MRIs demonstrated asymmetric facet joints, some being small others being enlarged, as well as deformed intervertebral foramina. The vertebral bodies varied in size and several small spinal disc herniations were also demonstrated. Some nerve roots seemed enlarged, but there was no affection of the spinal cord.

Histologic examination of affected and unaffected muscles did not identify any specific features, indicating that the patient had true muscular enlargement, and not pseudohypertrophia caused by infiltrating adipose or fibrous tissue. See Figure S1 for histology images of affected and unaffected muscle.
Due to the contractures of the fingers and painful cramps in the lumbrical muscles of the hands, the patient was treated with injections with botulinum toxin type A toxin every three months since the age of 18 . Also, she had weekly occupational therapy to preserve hand function. Hand surgery has been attempted to improve function, but these procedures have been of no benefit to the patient; in contrary the operations have been followed by muscular enlargement.

On physical examination at the age of 20 years, the patient's height was $159 \mathrm{~cm}$ and the weight was $52 \mathrm{~kg}$. A lipomatous truncal mass extended into the surrounding tissues of the upper back, and shoulder and into the neck webbing. The shoulders and arms were enlarged with a very muscular appearance (Fig. 1A-C). The palms were abnormally broad at the level of the metacarpi with an increased interval between the second and third fingers. The fingers were slender and of normal length. She had contractures of fingers, palms, and elbows. Both wrists were fixed in extension when relaxed (Fig. 1D,E). There were neither skin abnormalities in the palms or soles, nor skin abnormalities elsewhere or any remarkable epidermal nevi. Furthermore, there were no abnormalities of the head, lower body, legs, or feet (Fig. 1A, B, and F) and the patient had no dysmorphic facial features. Also, the patient had apparently normal intelligence, though this was not formally tested.

\section{METHODS}

\section{Sample Types}

Two independent muscle biopsies were obtained from affected muscle in the upper arm and one muscle biopsy was taken

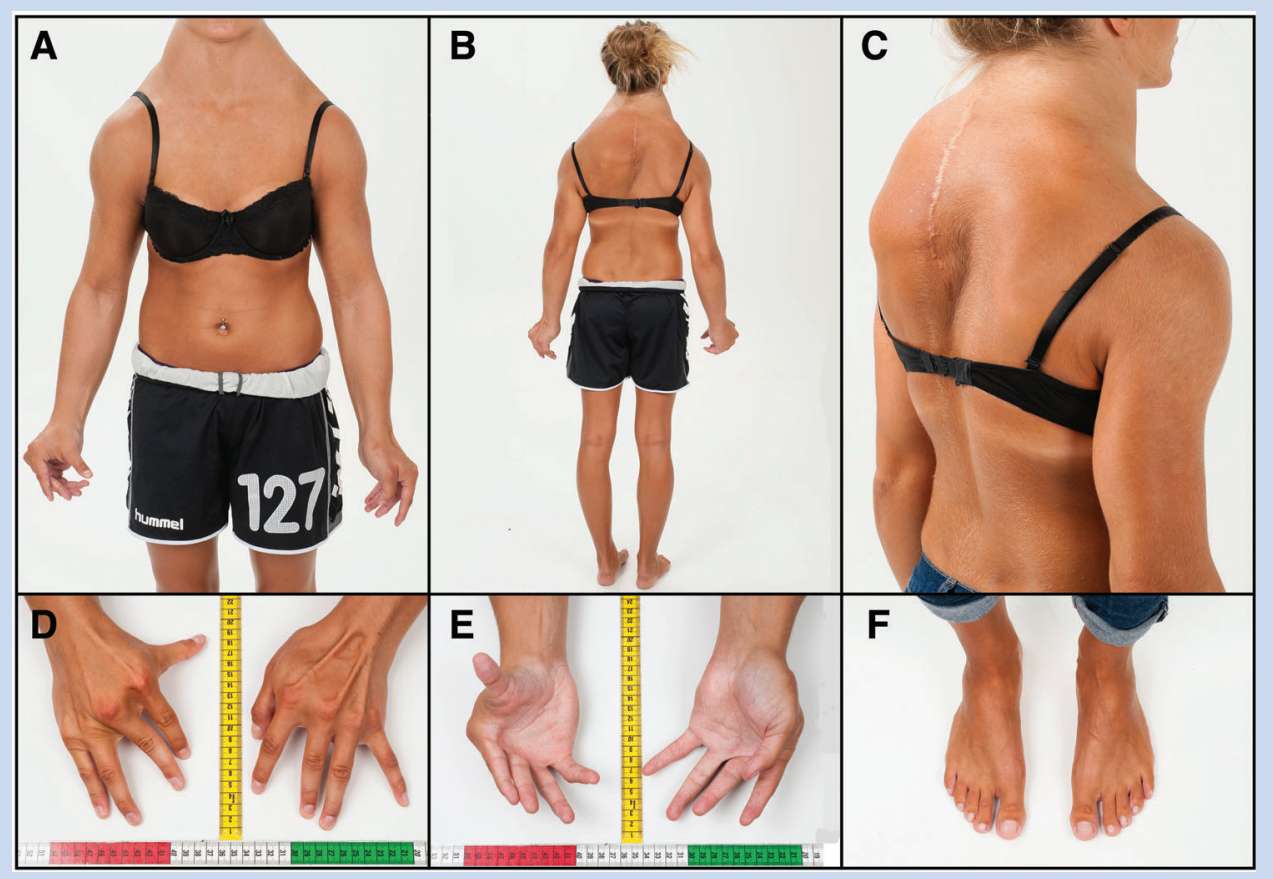

FIG. 1. Overgrowth features of patient. A: Neck webbing and enlarged shoulders and arms with a muscular apperance. B and C: Lipomatous truncal mass. $D$ and $E$ : Abnormally broad palms with an increased interval between the second and third fingers, and contractures of hands and fingers. F: No manifestations in the feet. 
from unaffected muscle in the thigh. A formalin-fixed paraffinembedded sample of lipoma tissue taken from surgery at the age of 11-month was also included. DNA was extracted from the tissue samples and from leukocytes using standard methods.

\section{Sequencing}

DNA samples from the first biopsy of affected muscle and from blood were examined by exome sequencing at Oxford Gene Technology. Untranslated regions (UTRs) were included in the analyses. Otherwise, the exome sequencing was performed according to Oxford Gene Technology standard somatic mutation analysis pipeline [Larson et al., 2012]. A minimum of $95 \%$ of the on-target regions was covered to a depth of at least $20 \times$.

Exome data were analyzed using the SomaticSniper software [Larson et al., 2012]. Further, filtering the data for "SeriousNon-synonymous Coding variants" showed variants numbers 1-13 listed in Table SI. Filtering the data for "Serious Stop Gained variants" identified one variant (variant number 14 in Table SI). Filtering the data for "Serious-Essential Splice Site variants," "Serious Stop Loss," "Serious-Frameshift Coding variants," or "Serious-Complex INDELS" did not show any variants. Relevant findings were confirmed by Sanger sequencing using BigDye ${ }^{\circledR}$ Terminator v1.1 Cycle Sequencing Kit. The procedure was carried out according to the description of the manufacturer (Applied Biosystems, Life Technology, Naeruum, Denmark). The sequence reaction was analyzed by using ABI 3500xl Genetic Analyzer (Life Technologies). Primer sequences and other PCR details are available upon request. Nucleotide numbering was according to HGVS standards using reference sequence NM_006218.2 and NP_006209.2. Written informed consent for whole exome sequencing was obtained from the patient.

\section{RESULTS}

Exome data from leukocytes and affected muscle tissue were compared using the SomaticSniper software. Fourteen candidate variants were identified, 13 of which were either artifacts of the analysis and/or most likely of no clinical relevance. See Table SI for the evaluation of the variants. The variant c.3140A $>\mathrm{G}$ in the PIK3CA gene has previously been observed in cancer cells and in patients with overgrowth syndromes [Samuels et al., 2004; Kurek et al., 2012; Rios et al., 2013]. Position 3140 in the PIK3CA gene in affected muscle was analyzed in a total of 75 reads in both directions and of these, 21 reads identified the variant suggesting a variant allele frequency of approx. 30\%. In DNA from leucocytes, only the wild type allele was detected (148 reads).

Sanger sequencing for presence of the c.3140A $>\mathrm{G} P I K 3 C A$ variant was performed on DNA from the second sample from affected muscle, the sample from unaffected muscle, leucocytes, and lipoma. This confirmed the presence of the mutation in mosaic form in affected muscle, and the absence of the variant in blood. In addition, the mutation was not seen in unaffected muscle, whereas mosaicism for the mutation was detected in the lipoma. See Figure S2 for Sanger sequencing results.

\section{DISCUSSION}

Like most other patients previously reported with mosaicism for a mutation in PIK3CA [Sapp et al., 2007; Lindhurst et al., 2012], the patient was considered to have Proteus syndrome during childhood though she clearly did not fulfill the diagnostic criteria of Proteus syndrome and at the age of 10 years, this diagnosis was rejected and the diagnosis was changed to "an unknown segmental overgrowth syndrome."

By exome sequencing and SomaticSniper software comparing the results from affected tissue and leucocytes, the c.3140A $>\mathrm{G}$ variant in the PIK3CA gene was identified in the affected tissue, only. This is a missense mutation that predicts a change in a conserved region of the $\mathrm{p} 110 \alpha$ protein (p.His1047Arg). This mutation has previously been reported in affected tissue in two patients with CLOVES syndrome, in seven patients with fibroadipose hyperplasia and in three patients with Klippel-Trénaunay syndrome as well as in two patients with type 1 macrodactyly [Kurek et al., 2012; Lindhurst et al., 2012; Rios et al., 2013]. To our knowledge, a germ line PIK3CA c.3140A > G (p.His1047Arg) mutation has not been reported.

The exome sequencing of affected and unaffected tissue exemplifies a methodological approach for genetic diagnostics in conditions caused by mosaicism.

The patient presented here had phenotypic characteristics of CLOVES syndrome as well as fibroadipose hyperplasia (Fig. 1). She had the typical congenital upper truncal lipomatous mass as reported in the majority of patients with CLOVES syndrome and she had mild spinal anomalies and broad palms as also described in previous patients. Neither MRI nor physical examination demonstrated vascular malformations, which is a major feature in CLOVES syndrome. Also, the patient did not have any epidermal nevi. The overgrowth is segmental as described in fibroadipose hyperplasia. However, the overgrowth predominantly affected muscular and adipose tissue and not predominantly fibrous and adipose tissue as reported in fibroadipose hyperplasia [Lindhurst et al., 2012].

One patient reported by Rios et al. [2013] also had true muscular enlargement. This patient was considered to have type 1 macrodactyly and muscular hemihypertrophy. An activating PIK3CA mutation was identified in affected muscle and in macrodactylous nerve tissue [Rios et al., 2013].

These findings demonstrate that not all patients with mosaicism for a PIK3CA mutation have a phenotype that fits into an existing disease category. However, our findings link together CLOVES syndrome and fibroadipose hyperplasia as conditions within the same spectrum of somatic overgrowth syndromes. As the phenotype depends on when the somatic variant arise during embryonic development and of the cell lines involved, it is expected that somatic mutations will cause a wide spectrum of disease manifestations.

\section{ACKNOWLEDGMENTS}

We wish to thank the patient for contributing to the report. 


\section{REFERENCES}

Alomari AI. 2009. CLOVE(S) syndrome: Expanding the acronym. Am J Med Genet Part A 149A:294.

Kurek KC, Luks VL, Ayturk UM, Alomari AI, Fishman SJ, Spencer SA, Mulliken JB, Bowen ME, Yamamoto GL, Kozakewich HP, Warman ML. 2012. Somatic mosaic activating mutations in PIK3CA cause CLOVES syndrome. Am J Hum Genet 90:1108-1115.

Larson DE, Harris CC, Chen K, Koboldt DC, Abbott TE, Dooling DJ, Ley TJ, Mardis ER, Wilson RK, Ding L. 2012. SomaticSniper: Identification of somatic point mutations in whole genome sequencing data. Bioinformatics 28:311-317.

Lindhurst MJ, Parker VE, Payne F, Sapp JC, Rudge S, Harris J, Witkowski AM, Zhang Q, Groeneveld MP, Scott CE, Daly A, Huson SM, Tosi LL, Cunningham ML, Darling TN, Geer J, Gucev Z, Sutton VR, Tziotzios C, Dixon AK, Helliwell T, O'Rahilly S, Savage DB, Wakelam MJ, Barroso I, Biesecker LG, Semple RK. 2012. Mosaic overgrowth with fibroadipose hyperplasia is caused by somatic activating mutations in PIK3CA. Nat Genet 44:928-933.

Mirzaa G, Conway R, Graham JM, Dobyns WB. 2013. PIK3CA-related segmental overgrowth. In: Pagon RA, Adam MP, Bird TD, Dolan CR,
Fong CT, Stephens K, editors. GeneReviews [Internet]. Seattle, WA: University of Washington. p 1-18.

Rios JJ, Paria N, Burns DK, Israel BA, Cornelia R, Wise CA, Ezaki M. 2013. Somatic gain-of-function mutations in PIK3CA in patients with macrodactyly. Hum Mol Genet 22:444-451.

Samuels Y, Wang Z, Bardelli A, Silliman N, Ptak J, Szabo S, Yan H, Gazdar A, Powell SM, Riggins GJ, Willson JK, Markowitz S, Kinzler KW, Vogelstein B, Velculescu VE. 2004. High frequency of mutations of the PIK3CA gene in human cancers. Science 304:554.

Sapp JC, Turner JT, van de Kamp JM, van Dijk FS, Lowry RB, Biesecker LG. 2007. Newly delineated syndrome of congenital lipomatous overgrowth, vascular malformations, and epidermal nevi (CLOVE syndrome) in seven patients. Am J Med Genet Part A 143A: 2944-2958.

\section{SUPPORTING INFORMATION}

Additional supporting information may be found in the online version of this article at the publisher's web-site. 